\title{
PREVALENCE AND ASSOCIATED FACTORS IN THE DECLINE OF RENAL FUNCTION AMONG OUTPATIENTS ATTENDING A COMMUNITY HOSPITAL, CENTRAL THAILAND
}

\author{
Chatchaya Chamnanmont ${ }^{*}$, Napat Chaiyakham $^{* *}$, Sittirat Kaensingh ${ }^{* * *}$, Wisit Kaewput ${ }^{* * * *}$, \\ Ram Rangsin ${ }^{* * * *}$, Boonsub Sakboonyarat ${ }^{* * * *}$
}

\author{
*Queen Savang Vadhana Memorial Hospital, Chonburi, Thailand \\ ${ }^{* *}$ Fort Kawila Hospital, Chiang Mai, Thailand \\ ${ }^{* * *}$ Fort Chakrabongse Hospital, Prachin Buri, Thailand \\ ***** Department of Military and Community Medicine, Phramongkutklao College of Medicine, \\ Bangkok, Thailand
}

\begin{abstract}
Introduction: Chronic kidney disease (CKD) is recognized as global public health issue especially affecting developing countries including Thailand. The epidemiologic data in the decline of renal function and the risk factors among Thai patients especially in community hospital settings were limited.

Methods: A cross-sectional study was conducted to identify the prevalence and associated risk factors in the decline of renal function among outpatients in Thaluang Community Hospital, Lop Buri Province, central Thailand, between November 1, 2018 and October 31, 2019. The decline in renal function was defined by glomerular filtration rate (GFR) $<60 \mathrm{~mL} / \mathrm{min} / 1.73 \mathrm{~m}^{2}$. Multivariate logistic regression analysis was performed to obtain the adjusted odds ratios (AOR) and $95 \%$ confidence interval (CI) of the factors related to the decline of renal function.

Results: A total of 874 outpatients participated in the study. The overall prevalence in the decline of renal function $\left(\mathrm{eGFR}<60 \mathrm{~mL} / \mathrm{min} / 1.73 \mathrm{~m}^{2}\right)$ was $20.3 \%(95 \% \mathrm{CI} ; 17.5 \%-22.9 \%)$. Among male participants, the prevalence in the decline of renal function was $21.1 \%(95 \% \mathrm{CI} ; 16.7 \%-25.5 \%)$ while it totaled $19.7 \%(95 \% \mathrm{CI} ; 16.3 \%-23.1 \%)$ among females. The independent associated factors in the decline of renal function included greater age (AOR 1.07; 95\% CI=1.05-1.09), history of NSAIDs used (AOR 2.97; 95\% $\mathrm{CI}=1.85-4.79)$ and elevated pulse pressure $(\mathrm{PP})>75^{\text {th }}$ percentile $(\mathrm{AOR} 1.64 ; 95 \%$ $\mathrm{CI}=1.07-2.53)$

Conclusion: We reported the prevalence in the decline of renal function among outpatients in a Thai community hospital which was comparable with the national level. Advanced age, history of NSAIDs used and PP were related to reduced kidney function. Therefore, effective health interventions should be conducted especially, appropriate NSAIDs used among outpatients.
\end{abstract}

Keywords: Decline of renal function, Community hospital, NSAIDs, Pulse pressure, Prevalence, Thailand

J Southeast Asian Med Res 2021: 5(2): 58-66

https://www.jseamed.org

Correspondence to:

Sakboonyarat B, Department of Military and Community Medicine, Phramongkutklao College of Medicine, Bangkok, Thailand 10400

E-mail: boonsub1991@pcm.ac.th

Received: 23 June 2021

Revised: 8 August 2021

Accepted: 12 August 2021 


\section{Introduction}

At present, chronic kidney disease (CKD) is recognized as a global public health issue and a major health problem, especially affecting developing countries. ${ }^{(1)}$ In Thailand, many people, particularly in rural areas, experience CKD and its complications; moreover, patients with end stage renal disease face difficulties when it comes to hospital costs. ${ }^{(2)}$ In 2009 one related study in Thailand reported the prevalence of CKD stage III-IV was 7.8 and $9.3 \%$ among Thai men and women, respectively; additionally, the study demonstrated that the prevalence of CKD was higher in the Bangkok Metropolitan. ${ }^{(3)}$ A 10 -year population-based study in Norway demonstrated that mean estimated change in glomerular filtration rate (GFR) was $-1.03 \mathrm{ml} / \mathrm{min} / 1.73 \mathrm{~m}^{2} /$ year; additionally, females was associated with slower decline in GFR.${ }^{(4)}$ Furthermore, patients with rapid decline measured by eGFR tended to increase risk of cardiovascular diseases and mortality. ${ }^{(5)}$

The risk factors for the decline of renal function include advanced age, noncommunicable diseases such as type 2 diabetes (T2D), hypertension (HT), hyperuricemia, history of kidney stones and history of using traditional medicine. . $^{(3,6,7)}$ Moreover, some factors bring about the rapid decrease of eGFR among patients indicating disease progression. ${ }^{(8)}$

However, epidemiologic data in the decline of renal function $\left(\mathrm{GFR}<60 \mathrm{~mL} / \mathrm{min} / 1.73 \mathrm{~m}^{2}\right)$ and the risk factors among Thai patients especially in community hospital settings were limited. Therefore, this study collected data from Thaluang Hospital, Lop Buri Province, central Thailand to determine the prevalence in the decline of renal function and associated factors among outpatients attending this community hospital. The results of the present study emphasized that the decline of renal function should be recognized as a serious health problem in Thailand.

\section{Methods}

\section{Study designs and subjects}

A hospital-based cross-sectional study was conducted to identify the prevalence and associated risk factors for the decline of renal function among outpatients in Thaluang Community Hospital, located in a rural area of Lop Buri Province, about $190 \mathrm{~km}$ from Bangkok. Inclusion criteria for the study consisted of patients aged at least 18 years attending the outpatient department of Thaluang Hospital between November 1, 2018 and October 31, 2019. Any patient not presenting a history of serum creatinine testing and eGFR during the period of study was excluded. The study was reviewed and approved by the Royal Thai Army Medical Department Institutional Review Board (approval number S035h/63_Exp).

\section{Data collection}

A standardized case report form was used to collect the data from electronic medical records by the investigators. Collected data included (1) demographic data which comprised age, sex, weight, and height (2) risk behaviors and comorbidities including smoking, alcohol consumption, T2D, HT, and dyslipidemia (DLP) (3) systolic blood pressure (SBP), diastolic blood pressure (DBP) and (4) serum creatinine level and estimated GFR. In addition, history of nonsteroidal anti-inflammatory drugs (NSAIDs) used among individuals was reviewed and collected. Body mass index (BMI) was calculated as body weight in kilograms divided by height in meters squared. The pulse pressure (PP) was calculated as the difference between SBP and DBP levels. According to the International Classification of Diseases, Tenth Revision Codes (ICD-10), T2D, HT and DLP were determined by E11, I10-I13 and E78, respectively. ${ }^{(9)}$ Isotope Dilution-Mass Spectrometry traceable enzymatic method was used for the measurement of serum creatinine and eGFR was calculate by CKD-EPI equations. ${ }^{(10)}$ The decline of renal function was defined by eGFR $<60 \mathrm{~mL} /$ $\mathrm{min} / 1.73 \mathrm{~m}^{2}{ }^{(11)}$

\section{Statistical analysis}

Data were analyzed using StataCorp. 2021. Stata Statistical Software: Release 17. College Station, TX, USA: StataCorp LLC. Demographic characteristics were presented using descriptive statistics. Categorical data were presented as number and percentage while continuous data were illustrated as mean and standard deviation (SD). Associated factors of the decline of renal 
function were analyzed using binary logistic regression analysis. The magnitude of association was manifested by crude odds ratio (OR) with 95\% confidence interval (CI). Multivariate logistic regression analysis was performed to obtain the adjusted odds ratios (AOR) and 95\% CI of the factors related to the decline of renal function. A $p$-value less than 0.05 was considered as statistical significance.

\section{Results}

A total of 874 outpatients were enrolled in the study. The average age of participants was $60.1 \pm 12.9$ years. The majority of participants were female (61.6\%). The average BMI was $25.3 \pm 5.0$ $\mathrm{kg} / \mathrm{m}^{2}$. One third of participants $(34.4 \%)$ had BMI from 25.0 to $29.9 \mathrm{~kg} / \mathrm{m}^{2}$. Among participants, the prevalence of HT and DM were 45.9 and $40.7 \%$, respectively. Almost $14 \%$ of the subjects had a history of smoking and alcohol consumption. The demographic data are shown in Table 1.
In all 874,177 outpatients had eGFR $<60$ $\mathrm{mL} / \mathrm{min} / 1.73 \mathrm{~m}^{2}$. The overall prevalence in the decline of renal function was $20.3 \%(95 \% \mathrm{CI}$; 17.5-22.9\%). Among male study participants, the prevalence in the decline of renal function was $21.1 \%(95 \% \mathrm{CI} ; 16.7-25.5 \%)$ while it totaled $19.7 \%$ (95\%CI; 16.3-23.1\%) among females. The prevalence in decline of renal function, stratified by age groups and sex, is illustrated in Figure 1.

Univariate and multivariate logistic regression analysis identifying the associated factors in the decline of renal function are shown in Tables 2 and 3. The independent associated factors in the decline of renal function included greater age (AOR 1.07; 95\%CI 1.05-1.09), history of NSAIDs used (AOR 2.97; 95\%CI 1.85-4.79) and elevated PP $>75^{\text {th }}$ percentile $(A O R 1.64 ; 95 \%$ CI 1.07-2.53).

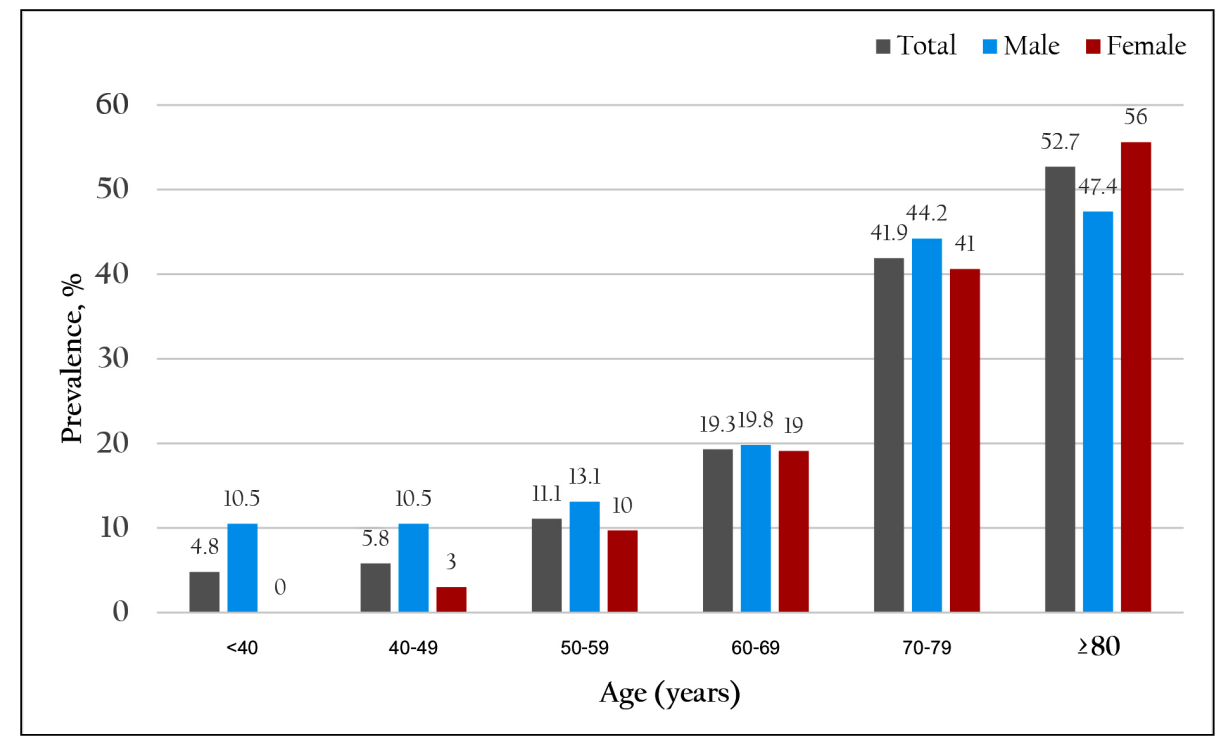

Figure 1. Prevalence of decline of renal function (eGFR $\left.<60 \mathrm{~mL} / \mathrm{min} / 1.73 \mathrm{~m}^{2}\right)$ stratified by age groups and sex

Table 1. Demographic characteristics of study participants

\begin{tabular}{lr}
\hline Characteristics & n (\%) \\
\hline Sex & \\
$\quad$ Male & $336(38.4)$ \\
$\quad$ Female & $538(61.6)$ \\
Age (years) & \\
$\quad$ mean \pm SD & $60.1 \pm 12.9$ \\
\hline
\end{tabular}


Table 1. Demographic characteristics of study participants (ext.)

\begin{tabular}{|c|c|}
\hline Characteristics & n (\%) \\
\hline median (max-min) & $60.0(98-18)$ \\
\hline$<40$ & $42(4.8)$ \\
\hline $40-49$ & $104(11.9)$ \\
\hline $50-59$ & $287(32.8)$ \\
\hline $60-69$ & $238(27.2)$ \\
\hline $70-79$ & $148(16.9)$ \\
\hline$\geq 80$ & $55(6.3)$ \\
\hline \multicolumn{2}{|c|}{ Body mass index $\left(\mathrm{kg} / \mathrm{m}^{2}\right)$} \\
\hline mean $\pm \mathrm{SD}$ & $25.3 \pm 5.0$ \\
\hline median (max-min) & $25.0(51.6-12.6)$ \\
\hline $18.4-22.9$ & $231(28.3)$ \\
\hline$<18.5$ & $46(5.6)$ \\
\hline $23.0-24.9$ & $137(16.8)$ \\
\hline $25.0-29.9$ & $281(34.4)$ \\
\hline$\geq 30.0$ & $121(14.8)$ \\
\hline \multicolumn{2}{|l|}{ Smoking } \\
\hline No & $755(86.4)$ \\
\hline Yes & $119(13.6)$ \\
\hline \multicolumn{2}{|l|}{ Alcohol drinking } \\
\hline No & $753(86.2)$ \\
\hline Yes & $121(13.8)$ \\
\hline \multicolumn{2}{|l|}{ Hypertension } \\
\hline No & $473(54.1)$ \\
\hline Yes & $401(45.9)$ \\
\hline \multicolumn{2}{|l|}{ Diabetes mellitus } \\
\hline No & $518(59.3)$ \\
\hline Yes & $356(40.7)$ \\
\hline \multicolumn{2}{|l|}{ Dyslipidemia } \\
\hline No & $854(97.7)$ \\
\hline Yes & $20(2.3)$ \\
\hline \multicolumn{2}{|c|}{ History of NSAIDs used } \\
\hline No & $528(60.3)$ \\
\hline Yes & $347(39.7)$ \\
\hline \multicolumn{2}{|c|}{ Glomerular filtration rate $\left(\mathrm{mL} / \mathrm{min} / \mathbf{1 . 7 3 \mathrm { m } ^ { 2 } )}\right.$} \\
\hline mean $\pm \mathrm{SD}$ & $80.3 \pm 24.0$ \\
\hline median (max-min) & $84.5(147.3-14.6)$ \\
\hline$>90$ & $358(41.0)$ \\
\hline $60-89$ & $339(38.8)$ \\
\hline $45-59$ & $99(11.3)$ \\
\hline $30-44$ & $46(5.3)$ \\
\hline $15-29$ & $30(3.4)$ \\
\hline$<15$ & $2(0.2)$ \\
\hline
\end{tabular}


Table 2. Univariate analysis for factors associated with decline of renal function

\begin{tabular}{|c|c|c|c|c|c|}
\hline Factors & $\begin{array}{c}\text { GFR }<60 \mathrm{~mL} / \\
\mathrm{min} / 1.73 \mathrm{~m}^{2} \\
\mathrm{n}(\%) \\
\end{array}$ & $\begin{array}{c}\mathrm{GFR} \geq 60 \mathrm{~mL} / \\
\min / 1.73 \mathrm{~m}^{2} \\
n(\%)\end{array}$ & $\begin{array}{l}\text { Odds } \\
\text { Ratio }\end{array}$ & $95 \% \mathrm{CI}$ & $p$-value \\
\hline \multicolumn{6}{|l|}{ Sex } \\
\hline Female & $106(19.7)$ & $432(80.3)$ & 1.00 & & \\
\hline Male & $71(21.1)$ & $265(78.9)$ & 1.09 & $0.78-1.53$ & 0.609 \\
\hline \multicolumn{6}{|l|}{ Age (years) } \\
\hline mean $\pm \mathrm{SD}$ & $68.2 \pm 12.1$ & $58.1 \pm 12.3$ & 2.85 & $2.30-3.54$ & $<0.001$ \\
\hline$<40$ & $2(4.8)$ & $40(95.2)$ & 1.00 & & \\
\hline $40-49$ & $6(5.8)$ & $98(94.2)$ & 1.22 & $0.24-6.32$ & 0.809 \\
\hline $50-59$ & $32(11.2)$ & $255(88.8)$ & 2.51 & $0.58-10.88$ & 0.219 \\
\hline $60-69$ & $46(19.3)$ & $192(80.7)$ & 4.79 & $1.12-20.55$ & 0.035 \\
\hline $70-79$ & $62(41.9)$ & $86(58.1)$ & 14.40 & $3.36-61.91$ & $<0.001$ \\
\hline$\geq 80$ & $29(52.7)$ & $26(47.3)$ & 22.31 & $4.90-101.55$ & $<0.001$ \\
\hline \multicolumn{6}{|c|}{ Body mass index $\left(\mathrm{kg} / \mathrm{m}^{2}\right)$} \\
\hline mean $\pm \mathrm{SD}$ & $25.3 \pm 4.7$ & $25.3 \pm 5.0$ & 1.00 & $0.96-1.03$ & 0.872 \\
\hline $18.4-22.9$ & $52(22.5)$ & $179(77.5)$ & 1.00 & & \\
\hline$<18.5$ & $4(8.7)$ & $42(91.3)$ & 0.33 & $0.11-0.96$ & 0.041 \\
\hline $23.0-24.9$ & $33(24.1)$ & $104(75.9)$ & 1.09 & $0.66-1.80$ & 0.729 \\
\hline $25.0-29.9$ & $46(16.4)$ & $235(83.6)$ & 0.67 & $0.43-1.05$ & 0.080 \\
\hline$\geq 30.0$ & $21(17.4)$ & $100(82.6)$ & 0.72 & $0.41-1.27$ & 0.258 \\
\hline \multicolumn{6}{|l|}{ Smoking } \\
\hline No & $148(19.6)$ & $607(80.4)$ & 1.00 & & \\
\hline Yes & $29(24.4)$ & $90(75.6)$ & 1.32 & $0.84-2.08$ & 0.230 \\
\hline \multicolumn{6}{|l|}{ Alcohol drinking } \\
\hline No & $148(19.7)$ & $605(80.3)$ & 1.00 & & \\
\hline Yes & $29(24.0)$ & $92(76.0)$ & 1.29 & $0.82-2.03$ & 0.274 \\
\hline \multicolumn{6}{|l|}{ Hypertension } \\
\hline No & $116(24.5)$ & $357(75.5)$ & 1.00 & & \\
\hline Yes & $61(15.2)$ & $340(84.8)$ & 0.55 & $0.39-0.78$ & 0.001 \\
\hline \multicolumn{6}{|l|}{ Diabetes mellitus } \\
\hline No & $73(14.1)$ & $445(85.9)$ & 1.00 & & \\
\hline Yes & $104(29.2)$ & $252(70.8)$ & 2.52 & $1.80-3.52$ & $<0.001$ \\
\hline \multicolumn{6}{|l|}{ Dyslipidemia } \\
\hline No & $177(20.7)$ & $677(79.3)$ & 1.00 & & \\
\hline Yes & $0(0)$ & $20(100.0)$ & N/A & N/A & N/A \\
\hline \multicolumn{6}{|l|}{ History of NSAIDs used } \\
\hline No & $61(11.6)$ & $466(88.4)$ & 1.00 & & \\
\hline Yes & $116(33.4)$ & $231(66.6)$ & 3.84 & $2.71-5.43$ & $<0.001$ \\
\hline \multicolumn{6}{|l|}{ Pulse pressure (mmHg) } \\
\hline$\leq 75$ percentile $(\leq 63)$ & $113(16.8)$ & $560(83.2)$ & 1.00 & & \\
\hline$>75$ percentile $(>63)$ & $62(32.1)$ & $131(67.9)$ & 2.35 & $1.63-3.37$ & $<0.001$ \\
\hline
\end{tabular}

NSAIDs; non-steroidal anti-inflammatory drugs, CI; confidence interval, SD; standard deviation 
Table 3. Multivariate analysis for factors associated with decline of renal function

\begin{tabular}{|c|c|c|c|}
\hline Factors & Adjusted Odds Ratio & $95 \% \mathrm{CI}$ & $p$-value \\
\hline \multicolumn{4}{|l|}{ Sex } \\
\hline Female & 1.00 & & \\
\hline Male & 1.06 & $0.66-1.70$ & 0.815 \\
\hline Age (years) & 1.07 & $1.05-1.09$ & $<0.001$ \\
\hline Body mass index $\left(\mathrm{kg} / \mathrm{m}^{2}\right)$ & 1.02 & $0.98-1.06$ & 0.309 \\
\hline \multicolumn{4}{|l|}{ Smoking } \\
\hline No & 1.00 & & \\
\hline Yes & 1.01 & $0.42-2.44$ & 0.991 \\
\hline \multicolumn{4}{|l|}{ Alcohol drinking } \\
\hline No & 1.00 & & \\
\hline Yes & 2.02 & $0.83-4.90$ & 0.119 \\
\hline \multicolumn{4}{|l|}{ Hypertension } \\
\hline No & 1.00 & & \\
\hline Yes & 0.96 & $0.53-1.72$ & 0.879 \\
\hline \multicolumn{4}{|l|}{ Diabetes mellitus } \\
\hline No & 1.00 & & \\
\hline Yes & 1.28 & $0.66-2.46$ & 0.464 \\
\hline \multicolumn{4}{|l|}{ History of NSAIDs used } \\
\hline No & 1.00 & & \\
\hline Yes & 2.97 & $1.85-4.79$ & $<0.001$ \\
\hline \multicolumn{4}{|l|}{ Pulse pressure (mmHg) } \\
\hline$\leq 75$ percentile $(\leq 63)$ & 1.00 & & \\
\hline$>75$ percentile $(>63)$ & 1.64 & $1.07-2.53$ & 0.024 \\
\hline
\end{tabular}

NSAIDs; non-steroidal anti-inflammatory drugs, CI; confidence interval

\section{Discussion}

The present study presented that the prevalence in the decline of renal function (eGFR $<60 \mathrm{~mL} /$ $\mathrm{min} / 1.73 \mathrm{~m}^{2}$ ) among outpatients was $20.3 \%$ which was higher than that of the 2010 national survey conducted in Thailand (9.3\%). ${ }^{(3)}$ In addition, compared with the prevalence of eGFR $<60 \mathrm{~mL} /$ $\mathrm{min} / 1.73 \mathrm{~m}^{2}$ in a Canadian community $(14.5 \%)$, the prevalence of those in this study was relatively high. ${ }^{(9)}$ According to the hospital-based study, the participants of the present study consisted of a high proportion of patients with T2D and HT, approximately $45 \%$; therefore, their comorbidities may have affected the decline of renal function leading to a high prevalence among the study participants. However, the prevalence in the decline of renal function among study participants was comparable with a related study in the UK reporting a prevalence of $18.2 \%$. ${ }^{(12)}$
Notably, the prevalence in the decline of renal function stratified by age groups significantly differed. We found that outpatients at higher age tended to be at risk in the decline of renal function. Currently, several countries have become aging societies; thus, the relationships between age and CKD have been reported from many studies. One related study conducted in a semi-urban community in Nigeria found that age was a significant factor of developing CKD. ${ }^{(13)}$ Additionally, recent studies in Thailand and Sri Lanka emphasized that the prevalence of CKD related to aging. ${ }^{(3,14)}$ Similarly, GFR measurement using single-nephron GFR, calculated in a healthy adult population in the US, demonstrated that CKD related to advanced age due to decreased glomerular infiltration in the normal aging process. A steep decline is observed after age 50 years. According to physiological processes, age 
is claimed to have immense results in decreased GFR. ${ }^{(13)}$ Many reasons explain this phenomenon. Firstly, long term contact with free radicals and oxidative stress results in declining numbers of normal functional podocyte but increasing numbers of sclerosed glomeruli. Secondly, aging kidneys exhibit structural changes in both microand macroanatomical aspects. Microanatomical aspects are explained by increasing sclerosis score among aging adults as a result of atrophy of functioning tubular and interstitial fibrosis and arteriosclerosis while macroanatomical changes are due to decreasing kidney volume, thinner kidney parenchymal and abundance of kidney cysts. ${ }^{(15)}$

We found that almost $40 \%$ of participants presented a history of NSAIDs use; additionally, outpatients with a history of NSAIDs use tended to be at risk of significantly declining renal function. Likewise, one related study in China reported that NSAIDs use related to higher risk of CKD; moreover, using NSAIDs more than 48 months led to reduced renal function. ${ }^{(16)}$ Similarly, a community-based cohort study in Canada reported that exposure to high dose NSAIDs increased the risk of rapidly progressing of CKD. ${ }^{(17)}$

The phenomenon may be explained by the principal mechanism of NSAIDs action via the cyclooxygenase (COX) inhibitor pathway. COX enzyme inhibition disrupts the conversion of arachidonic acid to different prostaglandins such as prostaglandin E2, prostacyclins and thromboxanes, inducing kidney vasodilatation inhibition and reducing renal perfusion. ${ }^{(18)}$

Additionally, NSAIDs are one of a risk factors contributing to $\mathrm{CKD}$, especially in advance age. Prolong used of NSAIDs leads to chronic interstitial nephritis, known as CIN, papillary necrosis and finally, CKD. ${ }^{(19,20)}$

Our study suggested promoting effective interventions such as careful consideration before appropriately prescribing NSADs. In addition, health literacy regarding the risk factors in decline of renal function especially NSAIDs use should be provided to patients. ${ }^{(21)}$

Our study reported that elevated PP was associated with the decline of renal function. Similarly, the National Institute of Diabetes and
Digestive Kidney Diseases registry in the US demonstrated that PP significantly correlated to the decline of GFR levels. ${ }^{(22)}$ Additionally, one related cohort study found that among patients with CKD in stages IV and V, PP more than $80 \mathrm{mmHg}$ constituted a significant predictor for disease progression. ${ }^{(23)} \mathrm{PP}$ was identified as a strong independent predictor of rising ambulatory arterial stiffness index. The relationship between elevated PP and decline of renal function may be explained by the process of cardiovascular aging as in arterial stiffness at both macrovascular and microvascular. ${ }^{(24-26)}$ Therefore, PP might constitute a noninvasive proxy indicator for the decline of renal function. ${ }^{(27)}$

The study employed a cross-sectional survey, making it difficult to establish a cause-and-effect relationship between associated factors and decline of renal function. According to secondary data used for analysis, some variables were incomplete. Another limitation was the small sample size in the study; therefore, the association between well-known risk factors such as T2D, HT, smoking status and outcome could not be presented. The results of our study may not be generalized to the whole country but may reflect the real situation of outpatients attending a Thai community hospital.

To our knowledge, this study is the latest study of the decline of renal function among patients attending a Thai community hospital. The results emphasized that Thailand, a developing country, is experiencing a serious public health burden. The decline of renal function including CKDs should be recognized as a serious health problem. The Ministry of Public Health should raise more awareness of this issue among the national population to prevent the disease and alleviate its complications.

\section{Conclusion}

The prevalence of the decline of renal function among outpatients in a Thai community hospital was higher than that at the national level. It indicated that this constituted an essential health problem not only in urban areas but also in rural communities. Advanced age, a history of NSAIDs use and PP were related to reduced 
kidney function. Additionally, effective health interventions should be conducted especially, to ensure appropriate NSAIDs use among patients.

\section{Acknowledgements}

The authors express their grateful thanks to the director of Thaluang Hospital, Lop Buri Province, Thailand. The authors wish to thank the staff of the Department of Universal Health Coverage Services and Medical Statistics, Thaluang, Lop Buri Province, Thailand. Finally, the authors thank all the staff members of the Department of Military and Community Medicine, Phramongkutklao College of Medicine, for their support in completing this study.

\section{References}

1. Abraham G, Varughese $\mathrm{S}$, Thandavan $\mathrm{T}$, Iyengar A, Fernando E, Naqvi SA, et al. Chronic kidney disease hotspots in developing countries in South Asia. Clin Kidney J 2016; 9: $135-41$.

2. Awuah KT, Finkelstein SH, Finkelstein FO. Quality of life of chronic kidney disease patients in developing countries. Kidney Int Suppl 2013; 3: 227-9.

3. Ingsathit A, Thakkinstian A, Chaiprasert A, Sangthawan P, Gojaseni P, Kiattisunthorn K, et al. Prevalence and risk factors of chronic kidney disease in the Thai adult population: Thai SEEK study. Nephrol Dial Transplant 2010; 25: 1567-75.

4. Eriksen BO, Ingebretsen OC. The progression of chronic kidney disease: A 10-year populationbased study of the effects of gender and age. Kidney Int 2006; 69: 375-82.

5. Rifkin DE, Shlipak MG, Katz R, Fried LF, Siscovick D, Chonchol M, et al. Rapid kidney function decline and mortality risk in older adults. Arch Inter Med 2008; 168: 2212-8.

6. Kazancioğlu R. Risk factors for chronic kidney disease: an update. Kidney Int Suppl 2013; 3: 368-71.

7. Duan J, Wang C, Liu D, Qiao Y, Pan S, Jiang D, et al. Prevalence and risk factors of chronic kidney disease and diabetic kidney disease in Chinese rural residents: a cross-sectional survey. Sci Rep 2019; 9: 10408.
8. Tótoli C, Carvalho AB, Ammirati AL, Draibe SA, Canziani MEF. Associated factors related to chronic kidney disease progression in elderly patients. PloS One 2019; 14: e0219956

9. ICD-10 World Health Organization: international statistical classification of diseases and related health problems: $10^{\text {th }}$ reprint in 2015 . http://www.who.int/classifications

10. Levey AS, Stevens LA, Schmid CH, Zhang YL, Castro 3rd AF, Feldman HI, et al. A new equation to estimate glomerular filtration rate. Ann Intern Med 2009; 150: 604-12.

11. Levey AS, de Jong PE, Coresh J, Nahas ME 1., Astor BC, Matsushita K, et al. The definition, classification, and prognosis of chronic kidney disease: a KDIGO Controversies Conference report. Kidney Int 2011; 80: 17-28.

12. Hirst JA, Hill N, O’ Ordóñez CA, Lasserson D, McManus RJ,Ogburn E. et al. Prevalence of chronic kidney disease in the community using data from OxRen: A UK populationbased cohort study. Br J Gen Pract 2020; 70: e285-93.

13. Chukwuonye II, Ohagwu KA, Adelowo OO, Chuku A, Obi EC, Onwuchekwa U, et al. Prevalence and Predictors of Chronic Kidney Disease in a Semiurban Community in Lagos. Inter J Nephrol 2019; 2019: 1625837

14. Jayasekara JMKB, Dissanayake DM, Sivakanesan R, Ranasinghe A, Karunarathna RH, Priyantha Kumara GWG. Epidemiology of chronic kidney disease, with special emphasis on chronic kidney disease of uncertain etiology, in the North Central Region of Sri Lanka. J Epi 2015; 25: 275-80.

15. Delanaye P, Jager KJ, Bökenkamp A, Christensson A, Dubourg L, Eriksen BO, et al. CKD: A call for an age-adapted definition. J Am Soc Nephrol 2019; 30: 1785-1850.

16. Pan Y, Zhang L, Wang F, Li X, Wang H. Status of non-steroidal anti-inflammatory drugs use and its association with chronic kidney disease: A cross-sectional survey in China. Nephrol 2014; 19: 655-60.

17. Gooch K, Culleton BF, Manns BJ, Zhang J, Alfonso H, Tonelli M, et al. NSAID Use and Progression of Chronic Kidney Disease. Am J Med 2007; 120: 280.e1-7. 
18. Lucas GNC, Leitão ACC, Alencar RL, Xavier RMF, Daher EDF, Silva Junior GB da. Pathophysiological aspects of nephropathy caused by non-steroidal anti-inflammatory drugs. J Bras Nefrol 2019: 41: 124-30.

19. Levey AS, Coresh J. Chronic kidney disease. Lancet 2012; 379: 165-80.

20. Atta MG, Whelton A. Acute renal papillary necrosis induced by ibuprofen. Am J Ther 1997; 4 : 55-60.

21. Luanghirun P, Tanaboriboon P, Mahissarakul P, Lertvivatpong N. Prevalence and associated factors of regular nonsteroidal anti-inflammatory drugs used in a rural community, Thailand. Glob J Health Sci 2017; 9: 58.

22. Raina R, Polaconda S, Nair N, Chakraborty R, Sethi S, Krishnappa V, et al. Association of pulse pressure, pulse pressure index, and ambulatory arterial stiffness index with kidney function in a cross-sectional pediatric chronic kidney disease cohort from the CKiD study. J Clin Hypertens 2020; 22: 1059-69.

23. Townsend RR, Chirinos JA, Parsa A, Weir MA, Sozio SM, Lash JP, et al. Central pulse pressure in chronic kidney disease: A chronic renal insufficiency cohort ancillary study. Hypertension 2010; 56: 518-24.

24. Euswas N, Phonnopparat N, Morasert K, Thakhampaeng P, Kaewsanit A, Mungthin $\mathrm{M}$, et al. National trends in the prevalence of diabetic retinopathy among Thai patients with type 2 diabetes and its associated factors from 2014 to 2018. PLoS One 2021; 16: $\mathrm{e} 0245801$.

25. Steppan J, Barodka V, Berkowitz DE, Nyhan D. Vascular Stiffness and Increased Pulse Pressure in the Aging Cardiovascular System. Cardio Res Prac 2011; 2011: 263585.

26. Avolio AP, Kuznetsova T, Heyndrickx GR, Kerkhof PLM, Li JK-J. Arterial Flow, Pulse Pressure and Pulse Wave Velocity in Men and Women at Various Ages. In: Kerkhof PLM, Miller VM, editors. Sex-Specific Analysis of Cardiovascular Function Cham: Springer International Publishing; 2018. pp. 153-68.

27. Xiao W, Wen Y, Ye P, Wang F, Cao R, Bai Y, et al. Noninvasive central pulse pressure is an independent determinant of renal function. $\mathrm{J}$ Clin Hypertens 2020； 22: 234-42. 